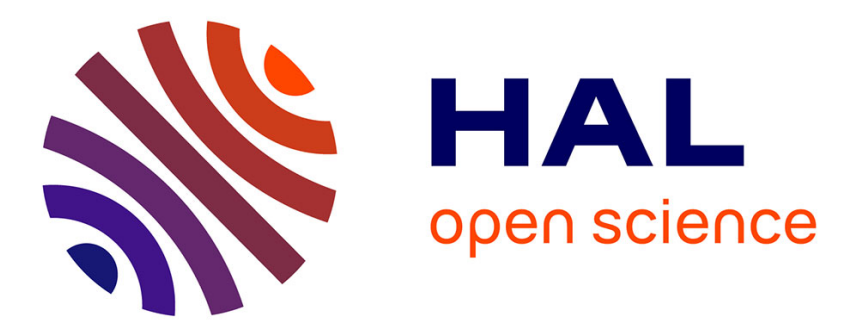

\title{
Collaboration between cardiologist and clinical pharmacist on prescription quality: What is the potential clinical impact for cardiology patients?
}

Yohan Audurier, Nicolas Chapet, Pierre Renaudin, Carole Bons, Betty

Mathieu, Sarah Theret, Gaëlle Barry, Anne Jalabert, Cyril Breuker, Florence Leclercq, et al.

\section{To cite this version:}

Yohan Audurier, Nicolas Chapet, Pierre Renaudin, Carole Bons, Betty Mathieu, et al.. Collaboration between cardiologist and clinical pharmacist on prescription quality: What is the potential clinical impact for cardiology patients?. International Journal of Clinical Practice, In press, 10.1111/ijcp.13531 . hal-02639599

\author{
HAL Id: hal-02639599 \\ https://hal.science/hal-02639599
}

Submitted on 26 Jun 2020

HAL is a multi-disciplinary open access archive for the deposit and dissemination of scientific research documents, whether they are published or not. The documents may come from teaching and research institutions in France or abroad, or from public or private research centers.
L'archive ouverte pluridisciplinaire HAL, est destinée au dépôt et à la diffusion de documents scientifiques de niveau recherche, publiés ou non, émanant des établissements d'enseignement et de recherche français ou étrangers, des laboratoires publics ou privés. 


\title{
Collaboration between cardiologist and clinical pharmacist on prescription quality: What is the potential clinical impact for cardiology patients?
}

\author{
Yohan Audurier $^{1,2}$ | Nicolas Chapet ${ }^{1}$ | Pierre Renaudin ${ }^{1,2,3}$ | Carole Bons ${ }^{1}$ | \\ Betty Mathieu $^{1}$ | Sarah Theret ${ }^{1}$ | Gaëlle de Barry ${ }^{1}$ | Anne Jalabert ${ }^{1}$ | Cyril Breuker ${ }^{1,2,4}$ \\ Florence Leclercq $^{2,5}$ | Jean-Luc Pasquie ${ }^{4,5}$ | Audrey Agullo ${ }^{5}$ | François Roubille ${ }^{4,5}$ | \\ Audrey Castet-Nicolas ${ }^{1,2,6}$
}

${ }^{1}$ Clinical Pharmacy Department, University Hospital, Montpellier, France

${ }^{2}$ Clinical Pharmacy Laboratory, University of Montpellier, Montpellier, France

${ }^{3}$ Faculty of Medicine Timone, Center for Studies and Research on Health Services and Quality of Life, University of Aix-Marseille, EA 3279, Marseille, France

${ }^{4}$ PhyMedExp, University of Montpellier, INSERM, CNRS, Montpellier, France

${ }^{5}$ Cardiology Department, University Hospital, Montpellier, France

${ }^{6}$ Cancer Research Institute of Montpellier (IRCM), INSERM U1194, ICM, Montpellier, France

\section{Correspondence}

Yohan Audurier, Clinical Pharmacy

Department, University Hospital,

Montpellier, France.

Email:yohan.audurier@yahoo.fr

\begin{abstract}
Objectives: The aim of this study was to determine the effect of pharmacists' interventions (PI) on the potential clinical impact of medication errors, including the lack of therapeutic optimisation of patients with cardiologic diseases, such as heart failure and acute coronary syndrome).

Methods: This was an observational, prospective study conducted in the cardiology department of a French university hospital centre for a duration of 9 months. All prescriptions were analysed and PI were registered for clinical rating by pharmacists and cardiologist.
\end{abstract}

Results: A total of $532 \mathrm{PI}$ cases were recorded in 339 patients, with a mean of 1.57 $( \pm 1.04) \mathrm{PI}$. The PI acceptance rate was $98.1 \%$. "Dose adjustment" and "introduction therapy" were the most common interventions and represented $38.0 \%$ and $32.9 \%$, respectively, of all PI. Statins were the most frequently involved drugs (18.1\%), followed by ACE (Angiotensin Converting Enzyme) inhibitors (10.9\%) and antiplatelet agents (9.3\%). Moreover, $13.8 \%$ of PI potentially avoided a severe or very severe clinical impact $(n=71)$ and $38.6 \%$ had a significant impact altering the quality of life $(n=198)$. There was no significant difference between the average score performed by the clinical pharmacist included in the cardiology team and the one obtained by the cardiologist ( $P=.797$ ). In contrast, a significant difference was observed for the average score established by the pharmacist localised in central pharmacy versus the rating of the cardiologist $(P<.001)$.

Conclusions: The collaboration between clinical pharmacists and cardiologists in the medical units seems to be beneficial to the quality of prescriptions, including the implementation of recommendations. The good rate of $\mathrm{PI}$ acceptance and the similar rating with the cardiologist show that there is a change in perspective of the pharmacist, being closer to the clinical reality. 


\section{1 | INTRODUCTION}

Medication errors (ME) and adverse drug events are two major public health challenges that have negative clinical and economic impacts. ${ }^{1}$ To address these issues, the French health authorities have implemented clinical pharmacy activities. ${ }^{2}$ In France, pharmacists are usually located in the central pharmacy in order to analyse drug prescriptions from all hospital medical units. Because of the lack of resources, very few teams are able to relocate the pharmacists into specific units. The target units are chosen based on criteria such as the complexity of patient care. The clinical pharmacist then acquires specialisation in unit care, in collaboration with the healthcare professionals.

In practice, the major activity of the clinical pharmacist is medication reconciliation (MR), which involves identification of the complete and correct list of a patient's current medications and comparison of this list with the hospital prescriptions. MR is conducted during different stages of the patient's hospitalisation to recognise and document discrepancies. ${ }^{3}$ Several studies have shown that this activity improves medication safety and decreases patient readmission. ${ }^{4-6}$ However, pharmacists can be involved in other steps of medication management, including medication review with therapeutic optimisation, drug therapy monitoring, and adverse drug reaction management. For example, Roblek et al and others have shown that the pharmacy team could improve drug prescription quality by means of pharmaceutical interventions $(\mathrm{PI})$ during hospitalisation. ${ }^{7,8} \mathrm{PI}$ is a proposition made by the pharmacists to the health care professionals who prescribe the drugs, regarding drug-related problems (DRP) such as ME, drug-drug interaction, drug monitoring or therapeuticoptimisation. These therapeutic optimisations can involve underprescription compared with guidelines, the choice of a drug according to the patient's profile, or medication modalities of administration. Although several studies have been published on PI, only a few of these have been conducted in the cardiology units. One such study is a non-randomised study in Brazil investigating $M R^{9}$ and the other one evaluated the discharge medication discrepancies. ${ }^{10}$

Acute decompensated heart failure (HF) and acute coronary syndrome (ACS) are probably the most common causes of hospitalisation in the cardiology units. Several studies, including clinical pharmacist interventions focused on these diseases have been published, but mainly about therapeutic educational activity. ${ }^{11-13}$ We aimed to evaluate the impact of other pharmaceutical activities during hospitalisation.

After consultation with the medical team of the cardiology department, regarding the utilization of the services of a clinical pharmacy team, we decided to record all the interventions made by pharmacists to verify whether pharmacists really acted on the therapeutic management of heart diseases or on the management of comorbidities. This study could allow identification of areas for improvement of prescription quality.

The aim of this study was to determine the effect of pharmacists' interventions $(\mathrm{PI})$ on the potential clinical impact of $\mathrm{ME}$, including

\section{What's known}

- The role of clinical pharmacist in improving patient care, by his/her involvement in medication reconciliation at patient admission and discharge, is widely known. In addition, the pharmacist identifies medication errors and dispense explanations about the treatment directly to the patient.

\section{What's new}

- This article underlines the interest of a pharmaceutical presence directly in the medical unit to better collaborate with physicians. Through the example of cardiology, we show that this privileged collaboration makes it possible to improve the implementation of therapeutic recommendations. This study specifies the level at which the pharmacist intervenes in the medication strategy for patients with high cardiovascular risk.

the lack of therapeutic optimisation of patients with cardiologic diseases such as HF or ACS.

\section{2 | MATERIALS AND METHODS}

\section{1 | Study design}

This was an observational, non-comparative, prospective and monocentric study conducted in the cardiology department of the University Hospital Centre of Montpellier. This department included three units, composed of 15 beds in the intensive care unit and 64 beds in the standard hospitalisation unit. The period of the analysis was 9 months, between January 2016 and September 2016. All prescriptions were analysed during this period by the clinical pharmacy team. The interventions collected were performed only by the pharmaceutical team located in the cardiology department, while the pharmacist located at the central pharmacy did not perform any intervention.

\section{2 | Clinical PI}

The pharmaceutical team, including a senior pharmacist, one resident and pharmacy students, were delocalised in the cardiology units with the aim of improving patients' medication management in the cardiology department with PI. The resident, together with the senior pharmacist, took turns to carry out these pharmaceutical optimisations, and the interventions performed by the students systematically reached the prescriber via the pharmacist. Moreover, the students carried out part of the MR, by alerting the pharmacist regarding potential errors, thus saving the pharmacist's time, 
which could be utilised to work closely with the medical team. DRP were identified both during MR at admission or discharge and during prescription analysis. Prescriptions for all patients were reviewed by a pharmacist on every working day, including during transfers between units (excluding the on-call period). The MR process was conducted according to an internal validated process, based on guidelines stated by the French authorities. Interventions were directly proposed orally during medical visits and staffs if a drugrelated problem was detected. DRP and PI were classified using the Act-IP tables of the French Society of Clinical Pharmacy (Appendix 1). Two items were added to evaluate cardiologic therapeutic optimisation, based on the European Society of Cardiology (ESC) recommendations: optimisation therapy concerning ACS and optimisation therapy concerning HF. ${ }^{14,15}$

\section{3 | Rating}

The potential clinical impact of all the detected drug-related problem was evaluated. The scale used to rate the significance of the DRP was based on the National Coordinating Council for Medication Error Reporting and Prevention (NCC MERP) Index for classifying ME and was adjusted to obtain four classes of severity: very serious, serious, moderate and minor, as described in a previous study published by Breuker et al. ${ }^{16} \mathrm{~A}$ potentially very serious consequence, such as an important overdose of drug with a narrow therapeutic index, was described as a drug-related problem that could affect the patient's prognosis. A potentially serious consequence was defined as a drug-related problem that may cause damage or increase hospital length of stay, such as omission of antiepileptic drugs. Potentially moderate and minor consequences were designated as DRP that affected the patients' quality of life and DRP, respectively whose impact on the patient was low or zero (Table 1). Of note, quality of life was not measured using a validated scale. It was an assumption made by the pharmacist or prescriber on the potential harm of the drug problem if not detected by the pharmacist.

This rating was performed by different health professionals, who evaluated in a blind manner the same cases. These professionals included a pharmacist localised in central pharmacy, a pharmacist delocalised in cardiology units, and a senior cardiologist, who was the head of the cardiologic intensive care unit. In addition to the anonymisation of the data, the scoring was carried out 1 year after the collection of the interventions, which reduced the bias in memorising the data.

\subsection{Data collection}

For each pharmaceutical intervention, the following data were collected: patients' demographic characteristics (age, sex), type of hospital unit, drug name, molecule name, the anatomical therapeutic chemical (ATC) class involved, type of DRP and type of correction proposed, together with acceptance of $\mathrm{PI}$. The time at which the intervention was performed (at admission [medication reconciliation], during hospitalisation or on discharge [medication reconciliation]) was also recorded. Cardiologic therapeutic optimisation and the potential clinical impact of ME on the patient were also collected. To extract only the most relevant interventions, we chose to exclude interventions that corrected drug-related problem as a result of computational errors (eg, unity error dispensing one milligram of a drug instead of one tablet).

\section{5 | Statistical analysis}

Patient characteristics were described as proportions for categorical variables and presented as means \pm standard deviations (SD) for quantitative variables. The Student $t$-test and Chi-squared test were carried out to obtain results. Statistical analysis was performed using the software R.

A declaration has been made to the National Commission of Informatics and Liberties (CNIL) for the use of these data. All procedures performed in this study, involving human participants, were in accordance with the ethical standards of the national research committee and with the 1964 Helsinki declaration and its later amendments. Only authors involved in the medical management of patients had access to the patients' identities and their medical data. Patient data were anonymised by removing any identifying information before being analysed.
TABLE 1 Potential clinical severity of DRP

\begin{tabular}{|lll|}
\hline Severity & Definition & Example \\
\hline Minor $=1$ & $\begin{array}{l}\text { DRP with low impact for } \\
\text { the patient }\end{array}$ & $\begin{array}{c}\text { Omission of a non-essential medication } \\
\text { (comfort medication) such as homoeopathy }\end{array}$ \\
\hline Moderate $=2$ & $\begin{array}{c}\text { DRP that upset patients' } \\
\text { quality of life }\end{array}$ & $\begin{array}{c}\text { Omission or low dosage of analgesic therapy } \\
\text { or anti-emetic medication ... }\end{array}$ \\
\hline Serious = 3 & $\begin{array}{c}\text { DRP that may cause } \\
\text { damage or may increase } \\
\text { hospital length of stay }\end{array}$ & $\begin{array}{c}\text { Low dosage or omission of antiepileptic drug } \\
\text { or anticoagulant drug ... }\end{array}$ \\
\hline Very serious = 4 & $\begin{array}{c}\text { DRP that could have } \\
\text { affected the patient's } \\
\text { prognosis }\end{array}$ & $\begin{array}{c}\text { High dosage of anticoagulant medication, } \\
\text { Digoxin or others drugs with a narrow } \\
\text { therapeutic index }\end{array}$ \\
\hline
\end{tabular}




\begin{tabular}{|lcc|}
\hline Type of DRP & Number of problems & $\begin{array}{c}\text { Percentage of } \\
\text { problems (\%) }\end{array}$ \\
\hline Untreated indication & 178 & 33.5 \\
\hline Overdose & 107 & 20.1 \\
\hline Underdose & 96 & 18.1 \\
\hline Improper administration & 52 & 9.8 \\
\hline Improper medication & 26 & 4.9 \\
\hline Contraindication & 22 & 4.1 \\
\hline Pharmaceutical consulting for medical application & 16 & 3.0 \\
\hline Interaction & 15 & 2.8 \\
\hline Follow-up & 9 & 1.7 \\
\hline Adverse effect & 5 & 0.9 \\
\hline Pharmaceutical consulting for paramedical & 4 & 0.8 \\
\hline application & & 0.4 \\
\hline Not administrated treatment & 2 & 100.00 \\
\hline Total & 532 & \\
\hline
\end{tabular}

TABLE 2 Distribution and proportions of DRP

\section{3 | RESULTS}

A total of $532 \mathrm{PI}$ were recorded for 339 patients, with a mean PI of $1.6( \pm 1.0)$ per patient and a maximum number of nine PI per patient. Most of our interventions were accepted (acceptance rate of $98.1 \%)$. The average age of the patients was $71.2( \pm 13.1)$ years. PI were mainly reported for male patients $(60.7 \%)$ and occurred only in $11.1 \%$ of the cases in the intensive care unit of cardiology, while this unit represented $23.0 \%$ of the beds.

\section{1 | Characteristics of DRP and PI}

The optimisation proposals were made following the detection of DRP, and the details of these therapeutic problems are described in Table 2.

The most frequent DRP were "untreated indication" (33.5\%) followed by "overdose" (20.1\%) and "underdose" (18.1\%). These problems were encountered as a result of a lack of prescription optimisation and forgetting to transcribe patients' usual treatments at admission.

The main $\mathrm{PI}$, corresponding to the detected problems, were identified, as shown in Table 3.

The activities of "dose adjustment" and "introduction therapy" were the most performed interventions $(38.0 \%$ and $32.9 \%$, respectively).

These interventions were implemented during several steps after $M R$ and medication review during hospitalisation (pharmaceutical analysis, medical examination or either staff). The distribution of $\mathrm{PI}$ was equal amongst MR at admission and discharge $(n=258)$ and review of prescription during hospitalisation $(n=274)$. Pharmaceutical activities were complementary during the patient's stay.

With regards to the therapeutic classes, the cardiovascular system was the most important category involved in $\mathrm{PI}(25.8 \%)$,
TABLE 3 Distribution and proportions of PI

\begin{tabular}{|lcc|}
\hline Type of PI & Number of PI & $\begin{array}{l}\text { Percentage } \\
\text { of PI (\%) }\end{array}$ \\
\hline Dose adjustment & 202 & 38.0 \\
\hline Introduction therapy & 175 & 32.9 \\
\hline Switch & 54 & 10.2 \\
\hline $\begin{array}{l}\text { Optimisation of administration } \\
\text { modalities }\end{array}$ & 49 & 9.2 \\
\hline Stopping therapy & 35 & \\
\hline Therapeutic following & 9 & 6.6 \\
\hline Helping prescription & 7 & 1.7 \\
\hline Choice of administration way & 1 & 1.3 \\
\hline Total & 532 & 0.2 \\
\hline
\end{tabular}

followed by metabolism and gastric system (17.7\%), nervous system (15.0\%) and blood system (13.9\%) (Table 4).

Table 5 describes the types of drugs involved in PI, among the drugs used for cardiovascular disorders. Anticoagulant and antiplatelet agents were also included since they were used in the cardiology department.

The most important drugs concerned with PI were medications used in heart failure and acute coronary syndrome. Statins were frequently involved (18.1\%), followed by ACE inhibitors (10.9\%), antiplatelet agents (9.3\%) and beta blockers (9.3\%).

A description of the cardiovascular pathologies associated with our interventions is presented in Table 6.

As expected, the majority of our PI were concerning therapeutic optimisation of HF and ACS. However, a significant number of these interventions were also focused on other cardiovascular pathologies, such as other ischemic heart diseases, high blood pressure and arrhythmia. 
TABLE 4 Therapeutic classes involved in PI

\begin{tabular}{lcc|}
\hline Therapeutic classes (ATC) & $\begin{array}{l}\text { Number } \\
\text { of PI }\end{array}$ & $\begin{array}{c}\text { Percentage } \\
\text { of PI (\%) }\end{array}$ \\
\hline C. Cardiovascular system & 137 & 25.8 \\
\hline A. Metabolism and gastric system & 94 & 17.7 \\
\hline N. Nervous system & 80 & 15.0 \\
\hline B. Blood system & 74 & 13.9 \\
\hline J. Antiinfective drugs (systemic use) & 41 & 7.7 \\
\hline R. Respiratory system & 31 & 5.8 \\
\hline H. Hormonal systemic preparation, & 21 & 3.9 \\
\hline except insulin & & \\
\hline M. Muscular system & 20 & 3.8 \\
\hline L. Anticancer drug and & 18 & 3.4 \\
\hline immunomodulator agents & & \\
\hline G. Genitourinary system and sex & 8 & 1.5 \\
\hline hormones & & \\
\hline S. Sensory organs & 7 & 1.3 \\
\hline V. Various & 1 & 0.2 \\
\hline Total & 532 & 100.00 \\
\hline
\end{tabular}

\subsection{Clinical impact}

Lastly, the potential clinical impact of PI was evaluated. A total of $513 \mathrm{PI}$ were evaluated; $19 \mathrm{PI}$ were excluded because of the lack of information in the medical file. The details of the ratings are presented in Table 7.

Taking the rating made by the cardiologist as the reference, $13.8 \%$ of the $\mathrm{PI}$ potentially avoided a severe or very severe clinical impact for patients $(n=71)$ and $38.6 \% \mathrm{PI}$ had a significant impact on the quality of life of the patients ( $n=198$ ). Among the PI that avoided a severe or very severe potential clinical impact, $24 \%$ were concerned with antiplatelet or anticoagulant drugs.

The average rating scores provided by different healthcare professionals were compared. As shown in Figure 1, there was no significant difference between the average score of rating performed by the senior pharmacist in the cardiology team and the one provided by the cardiologist $(P=.797)$. More precisely, $60.0 \%$ of $\mathrm{PI}$ were evaluated at the same level by both the professionals. In contrast, a significant difference was observed in the average rating scores provided by the pharmacist localised in central pharmacy and the cardiologist or the pharmacist present in the cardiology unit $(P<.001)$, and only $34.0 \%$ of $\mathrm{PI}$ were evaluated at the same level of rating as provided by the cardiologist.

\section{DISCUSSION}

In this study, we evaluated the level and the extent of PI in a cardiology unit. Our results showed that the clinical pharmacists played an important role in detecting, preventing, and resolving medicationrelated problems. A total of $532 \mathrm{DRP}$ were detected in the 9-month
TABLE 5 Types of drugs used for cardiovascular diseases involved in $\mathrm{PI}$

\begin{tabular}{|c|c|c|}
\hline $\begin{array}{l}\text { Types of drugs use for } \\
\text { cardiovascular diseases }\end{array}$ & $\begin{array}{l}\text { Number of } \\
\text { optimisation }\end{array}$ & $\begin{array}{l}\text { Percentage of } \\
\text { optimisation (\%) }\end{array}$ \\
\hline Statin & 35 & 18.1 \\
\hline ACE inhibitor & 21 & 10.9 \\
\hline Antiplatelet agents & 18 & 9.3 \\
\hline Beta blockers & 18 & 9.3 \\
\hline Antivitamin $\mathrm{k}$ & 14 & 7.3 \\
\hline Low molecular weight heparin & 13 & 6.7 \\
\hline Diuretic of the handle & 10 & 5.2 \\
\hline $\begin{array}{l}\text { Antagonist of } \\
\text { mineralocorticoid receptors }\end{array}$ & 7 & 3.6 \\
\hline Direct oral anticoagulant & 6 & 3.1 \\
\hline Antiarrhythmic drugs & 6 & 3.1 \\
\hline Other vasodilator agents & 5 & 2.6 \\
\hline Calcium channel blockers DHP & 5 & 2.6 \\
\hline $\begin{array}{l}\text { Angiotensin receptor } \\
\text { antagonists }\end{array}$ & 4 & 2.1 \\
\hline Unfractionated heparins & 4 & 2.1 \\
\hline Ezetimibe & 3 & 1.6 \\
\hline PPAR alpha activators & 3 & 1.6 \\
\hline Statins and ezetimibe & 3 & 1.6 \\
\hline Thiazide diuretic & 3 & 1.6 \\
\hline $\begin{array}{l}\text { ACE inhibitor and thiazide } \\
\text { diuretic }\end{array}$ & 3 & 1.6 \\
\hline $\begin{array}{l}\text { Angiotensin receptor } \\
\text { antagonists and thiazide } \\
\text { diuretic }\end{array}$ & 2 & 1.0 \\
\hline Levosimendan & 2 & 1.0 \\
\hline $\begin{array}{l}\text { Calcium channel blockers (not } \\
\text { DHP) }\end{array}$ & 2 & 1.0 \\
\hline Various & 6 & 3.1 \\
\hline Total & 193 & 100 \\
\hline
\end{tabular}

TABLE 6 Distribution of PI involved in cardiovascular diseases

\begin{tabular}{|lcc|}
\hline Diseases & $\begin{array}{l}\text { Number of } \\
\text { optimisation }\end{array}$ & $\begin{array}{l}\text { Percentage of } \\
\text { optimisation (\%) }\end{array}$ \\
\hline $\begin{array}{l}\text { Heart failure } \\
\text { Acute coronary syndrom }\end{array}$ & 49 & 35.8 \\
$\begin{array}{l}\text { (ACS) } \\
\text { Ischemic heart disease }\end{array}$ & 24 & 24.8 \\
$\quad$ (except ACS) & 17 & 17.5 \\
\hline $\begin{array}{l}\text { High blood pressure } \\
\text { Arrhythmia }\end{array}$ & 6 & 12.4 \\
\hline Dyslipidemia & 3 & 4.4 \\
\hline Stroke & 3 & 2.2 \\
\hline Pulmonary hypertension & 1 & 2.2 \\
\hline Total & 137 & 0.7 \\
\hline
\end{tabular}


duration of the study. It was observed that PI were efficient and had an acceptance rate of $98.1 \%$. These results seem to be more important than those described in another recent publication ${ }^{17}$ and could probably be explained by the complete involvement of the senior pharmacist in the cardiologic units. The equal distribution of interventions detected by MR and prescription analysis demonstrates the complementarity of these two activities. Thus, the implementation of various clinical pharmacy activities is necessary to ensure the best pharmaceutical care. In $70.0 \%$ of the cases, PI were concerned with the introduction of a missing treatment or dose adjustment. This implied that the clinical pharmacist team played a key role in therapeutic management. It is suggested that the clinical pharmacists must receive continuous training on the recommendations of care for these pathologies.

The collaboration with clinical pharmacists is also helpful for the nurses to optimise drug administration modalities, such as crushing of tablets or the dilution of intravenous drugs.

Our clinical pharmacy team analysed cardiovascular prescriptions, focused especially on ACS and HF. The most frequent

TABLE 7 Repartition of rating (by level) for each healthcare professional

\begin{tabular}{llllr} 
& \multicolumn{4}{l}{ Level of rating } \\
\cline { 2 - 5 } & 1 & 2 & 3 & 4 \\
Professionals & 244 & 198 & 70 & 1 \\
\hline Cardiologist & 215 & 255 & 42 & 1 \\
$\begin{array}{l}\text { Pharmacist included in } \\
\text { cardiology team }\end{array}$ & 43 & 191 & 263 & 16 \\
$\begin{array}{l}\text { Pharmacist localised in central } \\
\text { pharmacy }\end{array}$ & & & & \\
\hline
\end{tabular}

therapeutic classes with ME were statins, ACE inhibitors, antiplatelet agents and beta blockers. A study by Sayed et al showed that the prescriptions of patients with ACS or HF frequently had ME. ${ }^{18}$ Despite the cardiologists having excellent knowledge of these drugs, the pharmacists can participate in the optimisation of the quality of these prescriptions, particularly with respect to the improvement in the implementation of guidelines. For example, the pharmacist can suggest increase in doses of drugs used in HF treatment, as recommended by the ESC. ${ }^{14}$ Hassan et al reported encouraging results about the pharmacists' role in reducing discharge $\mathrm{ME}$, and their interventions improved the utilisation rates of the recommended drugs by approximately $10.0 \% .{ }^{19}$ Concerning HF, Cohen-Solal et al proved with the results of the FUTURE survey, that an improvement in the prescription quality (especially in achieving the target doses of the prescribed drugs) is feasible by ignoring the apprehension of an adverse event or by increasing the dosage, not according to the well-being of the patient, but until the maximum tolerated dose. ${ }^{20}$

The clinical rating results indicated the importance of PI made by the pharmacists. Indeed, we observed that more than half of these interventions potentially prevented significant clinical impacts for the patient, especially in case of prescriptions of anticoagulants and antiplatelet agents. It is common knowledge that the management of anticoagulant treatment is critical in patients with atrial fibrillation. Haas et al reported an increase in chances of stroke, major bleeding, and all-cause mortality as a result of sub-optimal anticoagulant treatment. $^{21}$

Moreover, clinical rating results emphasised the specialisation of the pharmacist in the clinical unit. It was observed that there was no significant difference between the ratings provided by the cardiologists and those provided by the pharmacist delocalised in the

\section{Repartition of quotation by level for each professional}

Pharmacist localized in central pharmacy

Pharmacist included in cardiology team

diology team
Cardiologist

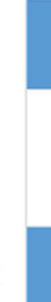

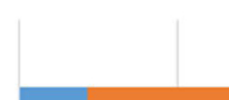

43

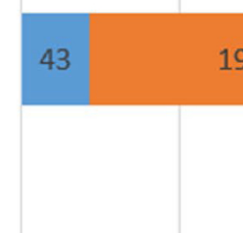

191
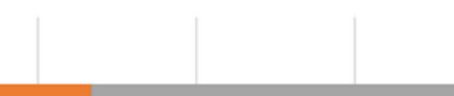
cardiology unit. In contrast, the ratings made by cardiologists and pharmacists localised in the central pharmacy were significantly different. This shared vision of the potential clinical impact for the patient is important because it is probably the explanation for the good rate of acceptance of $\mathrm{PI}$. We can assume that the $\mathrm{PI}$ made by pharmacists delocalised in cardiology units were more efficient than the PI made by pharmacists localised at the central pharmacy. This was an expected result, since the pharmacists located at the pharmacy were more multipurpose and could detect the most classic errors in various units. However, they usually do not get the opportunity or time to optimise treatments thoroughly. Compared with other countries, the number of beds per hospital pharmacist is high, and it is thus difficult to generalise our approach. The contribution of residents or pharmacy students in the medical units is then essential in order to maintain the links with the pharmacy. This study also showed the need for ongoing team awareness regarding the most common mistakes and new recommendations. This finding of poor knowledge, especially in case of the use of aldosterone antagonist, was reported in a previous study by Mayyas et al. ${ }^{22}$ It was observed that less than $40.0 \%$ of the interviewed physicians and pharmacists were aware of the recommendations for the use of aldosterone antagonists in $\mathrm{HF}$ management.

In the future, it would be interesting to set up a randomised controlled study versus control population to demonstrate the extent of contribution of the clinical pharmacist to criteria such as readmission. The economic evaluation of these optimisations will also be important data, the costs being reduced with this organisation, as suggested by Renaudin et al in the Orthopaedic and Trauma Surgery Department of our institution. ${ }^{23}$ To confirm this trend and overcome the limitations of this study, it would be appropriate to replicate a similar experience at several centres.

\section{CONCLUSION}

In conclusion, these results and the perceived satisfaction of the cardiology team (prescribers and nurses) encouraged us to continue this multidisciplinary approach. Beyond the numbers, this experience led to an improvement in the relationship and organisation between the cardiology department and the pharmacy. We believe that this successful collaboration can be eventually developed in consultations to continue to secure the patient's medication management after hospitalisation. As a follow-up to this study, we will be interested in a multicenter study to evaluate the impact of coordinated medical and pharmaceutical care on the re-admission rate of patients with heart failure.

\section{DISCLOSURES}

The author declares that he has no conflict of interest.

\section{REFERENCES}

1. Walsh EK, Hansen CR, Sahm LJ, et al. Economic impact of medication error: a systematic review. Pharmacoepidemiol Drug Saf. 2017;26:481-497.

2. Ordonnance $n^{\circ} 2016-1729$ du 15 décembre 2016 relative aux pharmacies à usage intérieur.

3. Rose AJ, Fischer SH, Paasche-Orlow MK. Beyond medication reconciliation: the correct medication list. JAMA. 2017;317:2057-2058.

4. Renaudin P, Baumstarck K, Daumas A, et al. Impact of a pharmacist-led medication review on hospital readmission in a pediatric and elderly population: study protocol for a randomized open-label controlled trial. Trials. 2017;18:65.

5. Breuker C, Abraham O, di Trapanie L, et al. Patients with diabetes are at high risk of serious medication errors at hospital: interest of clinical pharmacist intervention to improve healthcare. Eur J Intern Med. 2017;38:38-45.

6. De Oliveira GS, Castro-Alves LJ, Kendall MC, McCarthy R. Effectiveness of pharmacist intervention to reduce medication errors and health-care resources utilization after transitions of care: a meta-analysis of randomized controlled trials. J Patient Saf. 2017.

7. Roblek T, Deticek A, Leskovar B, et al. Clinical-pharmacist intervention reduces clinically relevant drug-drug interactions in patients with heart failure: a randomized, double-blind, controlled trial. Int J Cardiol. 2016;203:647-652.

8. Hohl CM, Partovi N, Ghement I, et al. Impact of early in-hospital medication review by clinical pharmacists on health services utilization. PLoS ONE. 2017;12:e0170495.

9. Magalhães GF, Santos GBNdC, Rosa MB, Noblat LdACB. Medication reconciliation in patients hospitalized in a cardiology unit. PLoS ONE. 2014;9:e115491.

10. Eggink RN, Lenderink AW, Widdershoven JWMG, van den Bemt PMLA. The effect of a clinical pharmacist discharge service on medication discrepancies in patients with heart failure. Pharm World Sci. 2010;32:759-766.

11. Jackevicius CA, de Leon NK, Lu L, et al. Impact of a multidisciplinary heart failure post-hospitalization program on heart failure readmission rates. Ann Pharmacother. 2015;49:1189-1196.

12. López Cabezas C, Falces Salvador C, Cubí Quadrada D, et al. Randomized clinical trial of a postdischarge pharmaceutical care program vs regular follow-up in patients with heart failure. Farm Hosp. 2006;30:328-342.

13. Wiggins BS, Rodgers JE, DiDomenico RJ, Cook AM, Page RL. Discharge counseling for patients with heart failure or myocardial infarction: a best practices model developed by members of the American College of Clinical Pharmacy's Cardiology Practice and Research Network based on the Hospital to Home $(\mathrm{H} 2 \mathrm{H})$ Initiative. Pharmacotherapy. 2013;33:558-580.

14. Ponikowski P, Voors AA, Anker SD, et al. 2016 ESC Guidelines for the diagnosis and treatment of acute and chronic heart failure: The Task Force for the diagnosis and treatment of acute and chronic heart failure of the European Society of Cardiology (ESC). Developed with the special contribution of the Heart Failure Association (HFA) of the ESC. Eur J Heart Fail. 2016;18:891-975.

15. Ibanez B, James S, Agewall S, et al. 2017 ESC Guidelines for the management of acute myocardial infarction in patients presenting with ST-segment elevation: The Task Force for the management of acute myocardial infarction in patients presenting with ST-segment elevation of the European Society of Cardiology (ESC). Eur Heart J. 2018;39:119-177.

16. Breuker C, Macioce V, Mura T, et al. Medication errors at hospital admission and discharge: risk factors and impact of medication reconciliation process to improve healthcare. J Patient Saf. 2017.

17. Al-Baghdadi H, Koca Al-Baghdadi Ç, Abdi A, et al. Introducing clinical pharmacy services to cardiovascular clinics at a university hospital in Northern Cyprus. Int J Clin Pharm. 2017;39:1185-1193. 
18. Ali MAS, Lobos CM, Abdelmegid MA-KF, El-Sayed AM. The frequency and nature of medication errors in hospitalized patients with acute coronary syndrome. Int J Clin Pharm. 2017;39: 542-550.

19. Hassan Y, Kassab Y, Abd Aziz N, Akram H, Ismail O. The impact of pharmacist-initiated interventions in improving acute coronary syndrome secondary prevention pharmacotherapy prescribing upon discharge. J Clin Pharm Ther. 2013;38:97-100.

20. Cohen Solal A, Leurs I, Assyag P, et al. Optimization of heart FailUre medical treatment after hospital discharge according to left ventricUlaR Ejection fraction. Arch Cardiovasc Dis. 2012;105:355-365.

21. Haas S, ten Cate H, Accetta G, et al. Quality of Vitamin K antagonist control and 1-year outcomes in patients with atrial fibrillation: a global perspective from the GARFIELD-AF Registry. PLoS ONE. 2016;11:e0164076.

22. Mayyas F, Ibrahim K, Alzoubi KH. Awareness of physicians and pharmacists of aldosterone antagonists in heart failure and myocardial infarction in Jordan. Pharm Pract. 2017;15:994.
23. Renaudin P, Coste A, Audurier Y, et al. Clinical, economic, and organizational impact of the clinical pharmacist in an orthopedic and trauma surgery department. J Patient Saf. 2018. 